\title{
Cultura Cultura
}

Revista de Historia Teoria das ldeaias - Revista de História e Teoria das Ideias

Vol. 30 | 2012

\section{A justiça na Antiguidade}

\section{O património da edição contemporânea portuguesa}

estado da questão

The publishers and their heritage: preserving, providing, studying and disseminating as emergency measures

\section{Daniel Melo}

\section{(2) OpenEdition}

\section{Journals}

\section{Edição electrónica}

URL: http://journals.openedition.org/cultura/1673

DOI: $10.4000 /$ cultura. 1673

ISSN: 2183-2021

\section{Editora}

Centro de História da Cultura

\section{Edição impressa}

Data de publição: 1 Dezembro 2012

Paginação: 173-190

ISSN: 0870-4546

\section{Refêrencia eletrónica}

Daniel Melo, « O património da edição contemporânea portuguesa », Cultura [Online], Vol. 30 | 2012 posto online no dia 30 setembro 2014, consultado a 01 maio 2019. URL : http:// journals.openedition.org/cultura/1673; DOI : 10.4000/cultura.1673

Este documento foi criado de forma automática no dia 1 Maio 2019

(c) CHAM - Centro de Humanidades / Centre for the Humanities 


\section{O património da edição contemporânea portuguesa}

estado da questão

The publishers and their heritage: preserving, providing, studying and

disseminating as emergency measures

Daniel Melo

1 Quando se fala em património cultural, uma área que costuma ficar na penumbra é a dos arquivos históricos. Isso deve-se em boa medida ao facto de o senso comum, incluindo os média, relacionar aquele universo com as grandes obras e monumentos, esquecendo que estes mobiliza(ra)m um amplo conjunto de acções e recursos para se afirmarem. Acções e recursos passíveis de reconstituição, estudo e divulgação graças a esses mesmos arquivos. No seio destes, um dos conjuntos particularmente vulneráveis é o dos arquivos de editoras e outros agentes da edição, por várias razões, em especial por o seu carácter maioritariamente privado não obrigar a um amparo público. Ou seja, tendo em conta que na maioria dos casos são arquivos privados, isto é, reunidos por entidades privadas, não estão automaticamente abrangidos pela protecção do organismo público nacional que tutela a área dos arquivos.

2 No entanto, a área dos arquivos tem um reconhecimento político-jurídico com algum lastro temporal. Por detrás desse reconhecimento está o labor de instituições e pessoas que cedo reconheceram a importância desse património, a necessidade da sua salvaguarda, tratamento, estudo, divulgação, valorização e disponibilização.

3 Este artigo propõe uma reflexão em torno do património arquivístico em geral e dos arquivos das editoras em particular, na sua articulação a nível internacional, bem como os seus efeitos a um nível nacional, através da análise do caso português. 


\section{0 enquadramento político-cultural e jurídico}

4 É usual abordar-se o património cultural como área consensual em termos de enunciação de políticas públicas (vd. Santos, 1998: 235 e ss.). Mas nem esta enunciação é isenta duma evolução histórica, com convergências e tensões, nem ela tem sempre uma aplicação consentânea com a ambição que lhe subjaz. Os documentos arquivísticos relevantes, objecto da presente reflexão, são uma parte substantiva desse mesmo património, culminando um percurso repartido por duas grandes etapas.

5 A primeira etapa inicia-se com a Revolução Francesa, quando uma parte dos documentos arquivísticos e bibliográficos passou a ser considerada reservatório cultural da nação, junto com os espaços que os continham: arquivos e bibliotecas custodiais (Poulot, 1997; Traniello, 1997; Ribeiro, 2008). Este marco expandiu-se gradualmente pelo mundo ocidental, verificando-se uma maior ênfase a partir dos alvores do século $\mathrm{XX}$, com a emergência das culturas nacionais na América Latina e das políticas culturais no Ocidente (Coelho, 1999).

6 A destruição infligida sobre o património ocidental pelas guerras de massas motivou um sobressalto cívico e político, que redundou em instrumentos jurídicos internacionais inovadores e de referência. É o caso da Convenção da UNESCO sobre a Protecção de Bens Culturais em Caso de Conflito Armado, adoptada em 1954, e que introduz o conceito de bem cultural. Aqui começa uma segunda etapa, que recebe impulso decisivo com os trabalhos da Comissão Franceschini (Comissão de inquérito sobre a protecção e valorização das coisas com interesse histórico, arqueológico, artístico e da paisagem, 1964-67), grupo de deputados e de peritos nomeado pelo governo italiano para elaborar as grandes linhas orientadoras da política cultural nacional e que foi responsável por um inovador aprofundamento conceptual do significado e alcance de bens culturais. Segundo a sua última recomendação, «Entende-se por Bem Cultural os Bens materiais testemunho da civilização», i. e., o bem cultural é um bem representativo da cultura do homem em sociedade e interessa ao conjunto dos países. Outro ponto relevante foi a abrangência do conceito: «Pertencem ao património cultural da Nação todos os bens que tenham referência à história da civilização. Estão submetidos a lei os bens de interesse arqueológico, histórico, ambiental e paisagístico, arquivístico e bibliográfico, bem como qualquer outro bem que constitua testemunho material com valor de civilização.» Esta definição foi de tal modo influente que seria adoptada internacionalmente dez anos depois, através da UNESCO, com as suas «Recomendações para a Protecção de Bens Culturais». ${ }^{1}$

7 Ainda nos anos 1960, peritos como Cesare Brandi e Giovanni Urbani lançam as bases teóricas da conservação preventiva, a qual engloba «todas as medidas e acções visando evitar e minimizar futura deterioração e perda» e se foca em colecções inteiras e no seu ambiente envolvente, pressupondo programação institucional de curta e média durações e suporte científico. ${ }^{2}$ Esta corrente de conservação patrimonial faria escola um pouco por todo o mundo e incide tanto em sítios e monumentos como nos bens arquivísticos e bibliográficos.

8 Em Portugal, a locução bens culturais entra na legislação exclusivamente nacional apenas em 1985 (lei n.․ 13/85), mas já estava incluída na sua arquitectura jurídica, se considerarmos os tratados internacionais que o país subscrevera, começando pela já 
mencionada convenção de Haia (1954), que define normas nos casos de roubo, pilhagem e vandalismo.

Outro marco jurídico é o decreto-lei n. 16/93, que estabeleceu o regime geral dos arquivos e do património arquivístico, considerando estes como «bens fundamentais que corporizam a cultura portuguesa» e merecedores de garantias para a sua «valorização, inventariação e preservação». ${ }^{3}$ Nele se incluem normas que podem servir para proteger os arquivos definitivos das editoras, sejam eles de entidades públicas, privadas ou associativas. Com efeito, este diploma de referência considera como bens susceptíveis de classificação «os arquivos e os documentos que, pelo seu relevante valor informativo ou probatório, devam merecer especial proteç̧ão», por conseguinte constituindo «objecto de classificação pelo Governo, sob proposta do órgão de gestão [então a Torre do Tombo, actualmente a Direcção-Geral de Arquivos]» (art. 21, ponto 1). Tal classificação pode incidir tanto em bens isolados como agrupados e «não afecta o direito de propriedade, mas impede a alteração, divisão ou destruição de arquivos ou de documentos sem aprovação prévia do órgão de gestão» (art. 21, pontos 2 e 3). 0 processo de classificação pode partir do órgão de gestão ou de outra entidade, seja ela pública ou privada (art. 22, ponto 1), o que possibilita que os editores tomem a iniciativa de solicitar esse processo. Estas disposições foram posteriormente actualizadas e aprofundadas na lei n. $107 / 2001 .^{4}$

Esta última, crismada Lei de Bases de Protecção e Valorização do Património Cultural Português, desenvolve a perspectiva jurídica portuguesa, considerando bens culturais os bens móveis e imóveis que «representem testemunho material com valor de civilização ou de cultura», porquanto "portadores de interesse cultural relevante» (arts. 2 e 14). Nela se consagrou igualmente a "conservação preventiva e programada» enquanto componente basilar do «regime geral de valorização dos bens culturais» (art. 70, alínea a)).

\section{Os arquivos das editoras como subconjunto relevante de bens culturais: contexto internacional e situação no caso português}

11 Dada a posição central dos editores e outros agentes da edição no contexto da criação, circulação e difusão culturais contemporâneas, tornou-se incontornável (ou apetecível) o estudo de partes dos seus arquivos. ${ }^{5}$ Essa apetência tem indícios relevantes no próprio campo da edição, com publicação de correspondência de escritores e outros autores, de fac-símiles de primeiras edições ou de inéditos, entre outras dimensões.

Não obstante, será no interior do campo académico e erudito que surgirá um investimento mais significativo e pioneiro, prova da importância precoce que parte das elites científicas e culturais vislumbraram nesses repositórios de informação que são os arquivos. Entre todas as iniciativas específicas, importa realçar as das seguintes instituições, pela sua visibilidade e influência: o Canadian Centre for Studies in Publishing (da Simon Fraser University, Canadá, desde 1987), o Institut d'histoire du livre (Lyon, França, 2001), a Reading University Library Collections (Reino Unido), o Scottish Archive of Print and Publishing History Records (SAPPHIRE, idem), a SHARP: Society for the History of Authorship, Reading and Publishing (EUA, desde 1991), o Centro di Ricerca Europeo Libro Editoria Biblioteca (Università Cattolica del Sacro Cuore, Milão, Itália), a Fondazione Arnoldo e Alberto Mondadori (Milão, Itália, desde 1979), a Fundación Germán 
Sánchez Ruipérez (Salamanca e Madrid, Espanha, desde 1981), o Instituto de Historia del Libro y de la Lectura (da Fundación San Millán, Espanha, 2000), a Fondation Mémoire Éditoriale (Suíça francófona, desde 1997) e o LIHED/ Grupo de Pesquisa sobre Livro e História Editorial no Brasil (Rio de Janeiro, Brasil, 2003).

Estas instituições traçam-nos uma geografia alinhando países europeus e americanos (França, Reino Unido, Itália, Espanha e Suíça; Canadá, EUA e Brasil). Desenvolvem trabalho em diferentes dimensões, do estudo, sensibilização e divulgação à preservação e valorização, sendo de realçar que a maioria se dedica ao investimento mais oneroso e complexo, o da salvaguarda e tratamento arquivístico dos fundos de editoras com relevante interesse cultural.

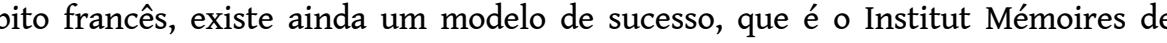
l'Édition Contemporaine (IMEC), que tem dimensão nacional mas foi criado em 1996 pela sinergia entre investigadores e profissionais da edição, a que depois se juntaram instituições públicas duma região, a Região da Baixa Normândia, e a Université de Caen Basse-Normandie (cf. IMEC, 2011a). Ou seja, não só não resultou dum impulso do Estado central como não tem tutela estatal, ao contrário do que costuma ocorrer em países de tradição centralista, como França e Portugal. Além de ter um espaço de conservação, tratamento e valorização de arquivos de edição de particulares, empresas e instituições (com noventa fundos em 2009), junta de modo invulgar um vasto conjunto doutras dimensões, como sejam a de ter um plano de publicações (desde 1987, actualmente com setenta títulos organizados em sete colecções), exposições e encontros descentralizados (desde 1989), biblioteca especializada (desde 2004), serviço educativo (desde 2008) e um pólo estratégico em Paris, que promove parcerias e redes (cf. IMEC, 2009 e 2011b).

Embora com um escopo mais centrado na promoção do livro actual, o Centre National du Livre, criado pelo governo francês em 1946, dispõe de linhas de financiamento para tarefas muitos concretas que têm ajudado na valorização e divulgação da memória editorial e são susceptíveis de ser emuladas noutras paragens. ${ }^{6}$

A preservação dos arquivos de casas editoriais tem sido acompanhada pelo estudo da documentação por diferentes áreas disciplinares (arquivística, literatura, história, antropologia, sociologia, economia, etc.) - existindo já um vasto conjunto de estudos ${ }^{7}$ - e pelo colmatar das suas lacunas através da produção de novas fontes históricas, por via de entrevistas (v.g., Ferreira, 2004; Bradley, 2009).

Quanto ao estudo, cabe salientar que este se reveste, por vezes, duma dimensão mais visível, externa, através de encontros abertos ao público em geral, de exposições, de sítios de internet e de guias que orientam na pesquisa. Entre os encontros e exposições mais recentes, destaco dois.

Em 2009, o IMEC organizou um grande encontro internacional, o «Colloque 20 Ans de Recherches sur l'Édition», para reforçar o laço entre editores e seus 'cronistas', por um lado, e para fazer um balanço dos estudos sobre a edição, por outro lado. Nele se abordaram de modo pioneiro as «diferentes políticas de colecta de arquivos editoriais na Europa, onde uma tendência geral se desenha: os meios utilizados para atender o crescente interesse de editores no que respeita aos seus arquivos permitem agora comparar práticas muito diferenciadas» (IMEC, 2009: 5).

19 De 2011 é outro evento dinamizado pelo IMEC, este reunindo as vertentes de estudo e mostra documental, o «Éditeurs: les lois du métier». A partir duma exposição transversal sobre as dimensões comportamental, económica e política convocadas pelo 
enquadramento jurídico do ofício de editor, organizou-se um colóquio e um sítio de internet próprios, este ainda passível de consulta e onde se disponibiliza informação sobre legislação, temas fortes (religião, banda desenhada, descolonização, Maio de 68, entre vários outros), grandes figuras e uma cronologia da edição em França. ${ }^{8}$

Dada a incidência particular deste artigo nas questões do tratamento e da valorização arquivísticas, creio ser pertinente destacar dois tipos de ferramentas, os trabalhos sobre arquivística e arquivos de editores, e os guias.

Os primeiros respeitam a uma área de estudos ainda em fase de consolidação, mas onde alguns autores têm feito um trabalho de referência, destacando-se: Laura Millar Coles, ligada a instituições especializadas como o Canadian Centre for Studies in Publishing (v.g., Coles, 1989 e Millar, 2009), colaboradores do IMEC (v.g., IMEC, 2009) e peritos italianos ligados às pujantes iniciativas italianas neste sector (v.g., Tortorelli, 1998; Braida \& Cadioli, 2007; Brunetti, 2011).

$\mathrm{Na}$ vertente dos guias, é no mundo anglo-saxónico que mais cedo se avançou na disponibilização para o público em geral da informação sobre o conjunto disponível de arquivos e documentação sobre editores, tanto quanto às listas específicas em si como quanto a sites que ordenam e disponibilizam o conteúdo dessas mesmas listas. ${ }^{9}$ Não obstante, o espaço europeu tem avançado bastante neste domínio, como se pode constatar na consulta da página de internet «European Publishing Links» (http:// www.europublishing.info/links/), que agrega hiperligações para organizações transeuropeias e para organizações sectoriais de 35 países europeus. Neste particular, França e Itália são dois dos países na dianteira, com múltiplos catálogos e repertórios genéricos, sectoriais e temáticos saindo regularmente. ${ }^{10}$

23 No domínio das entrevistas, realce para os arquivos de história oral do: SAPPHIRE, que desde 1998 disponibiliza na internet entrevistas a empregados do sector editorial escocês, por iniciativa dum consórcio entre a Napier University e a Queen Margaret University (ambas de Edimburgo, Escócia; Finkelstein, 2002); do Book Trade Lives (1997-2006), um programa de registo de testemunhos de editores realizado pelo British Library Sound Archive e com apoio mecenático da National Life Stories (British Library, s.d.); e do American Printing History Association's Oral History Project (EUA), um projecto recente para recolha de testemunhos de agentes seniores da edição norte-americana (American Printing History Association, s. d.). Ainda nos EUA, a Columbia University é a entidade detentora do maior número de arquivos de editoras, além de dispor de depoimentos gravados de editores no maior e mais antigo programa de história oral, que recua a 1948 (Columbia Center for Oral History, s. d.).

Neste particular, Portugal encontra-se muito atrasado: não há ainda uma entidade pública que assuma, de modo pró-activo, a responsabilidade pela prospecção, incorporação, tratamento arquivístico e disponibilização para consulta pública dos fundos documentais destas casas de cultura que são as editoras, e muito menos pela guarda das fontes de história oral. ${ }^{11}$ Sublinhe-se, contudo, que qualquer entidade pública ou privada pode solicitar a «abertura de um procedimento administrativo de classificação ou inventariação» de seus bens culturais, logo também dos que integram o património arquivístico (art. 25 da lei n.. 107/2001), sendo que a sua aprovação (via registo patrimonial de classificação ou inventariação) permitirá «aos proprietários, possuidores e demais titulares de direitos reais sobre os bens culturais classificados, o acesso aos regimes de apoio, incentivos, financiamentos e estipulação de acordos e outros contratos a que se refere o $\mathrm{n} .{ }^{\circ} 1$ do artigo $60 .$. , reforçados de forma proporcional ao maior peso das 
limitações» (art. 31). Ressalve-se, outrossim, que a Direcção-Geral de Arquivos pode vir a ser um destino possível de incorporação (através dos seus equipamentos específicos, incluindo a Torre do Tombo), carecendo de um reforço dos seus recursos humanos, pois actualmente está impossibilitada de tratar de modo exaustivo todos os fundos mais relevantes entretanto nela incorporados. Essa intervenção podia inspirar-se no exemplo do Museu do Neo-Realismo (Vila Franca de Xira), que em 1998 acolheu parte substancial do fundo das Edições Cosmos, através de protocolo. Pode equacionar-se uma solução de dispersão por várias instituições, como ainda a Biblioteca Nacional de Portugal (BNP), o Centro de Documentação 25 de Abril da Universidade de Coimbra ou a Fundação Mário Soares. ${ }^{12}$ Contudo, nenhuma destas instituições tem uma vocação específica claramente estabelecida nos seus estatutos ou diploma orgânico quanto à preservação, disponibilização e divulgação deste tipo de arquivos.

Os mecenas escasseiam nesta área, e são poucos os privados já sensibilizados para cooperar activamente, em termos logísticos, financeiros, etc., embora a actividade de colecta, digitalização e divulgação (via sítios de Internet) pelo estudioso, bibliófilo e político José Pacheco Pereira seja uma excepção que merece seguidores. Os próprios editores «não gostam de se revelar» (Martins, 1999: 26) e descuram grandemente o seu arquivo definitivo, o seu valor patrimonial e interesse público, à imagem do que ocorre em países como Espanha, Grécia e Holanda.$^{13}$ Assim, quando uma editora (ou uma livraria antiga, ou um alfarrabista, ou...) fecha portas (como recentemente sucedeu com a Publicações Europa-América), fica em perigo o seu rico arquivo: por espartilho entre vários donos (perdendo a sua coerência), por falta de condições adequadas de preservação da documentação, por interdição do seu acesso público (mesmo que condicionado). Perdese assim a oportunidade de se salvaguardarem fontes indispensáveis para o conhecimento da edição e dos agentes do livro, sua história, memória e património cultural.

Ora, esta situação tem influência negativa na própria capacidade de se estudarem essas editoras dum ponto de vista erudito e académico. Com efeito, são poucos os estudos específicos existentes para o período contemporâneo, apesar da qualidade da sua maioria. ${ }^{14} \mathrm{Na}$ bibliografia abarcada pelos guias especializados atrás referidos - onde predominam estudos incidindo na caracterização dos agentes, estratégias e conteúdos editoriais (maioritariamente para oitocentos) e no papel cultural, associativo e cívico dos editores e principais constrangimentos políticos (aqui já também alastrando para o Estado Novo) realce para Saraiva, 1979; Caeiro, 1980; Coelho, 1980; Domingos, 1985; Santos, 1985; Guedes, 1989 e 1993; Rodrigues, 1992-94 e 1999; Anselmo, 1997a e 1997b; Azevedo, 1997 e 1999; Leite, 1998; Pereira, 1998; Martins, 1999; Ribeiro, 1999. Na bibliografia específica não abarcada - onde se misturam abordagens biográficas, monográficas, temáticas e estudos sobre a edição mais actual (incluindo a digital e a economia da cultura) - cabem Rêgo \& Castelo-Branco, 2003; Martins, 2004 e 2005; Ferrão, Oliveira \& Fonseca, 2005; Seruya, 2005 e 2007; Curto, 2006; Furtado, 2007 e 2009; Matos, 2007; Pinheiro, 2007; Pita \& Trindade, 2008; Cravo, 2009; Medeiros, 2010; Neves \& Santos, 2010; Beja, 2012; Costa, 2012; Maués, 2012; Neves, 2012. É particularmente notória a insuficiência de estudos para finais do século XIX e todo o século XX. Em contrapartida, a época moderna é um período já consolidado (cf. guias bibliográficos supracitados). Registe-se também a gritante lacuna ao nível de inquéritos específicos, só muito recentemente tendo sido editado o estudo da OAC relativo a um inquérito à edição e a um inquérito à comercialização, com dados de 2007 (cf. Neves, 2012), tendo os restantes dois existentes ficado apenas na forma de relatórios não editados publicamente. ${ }^{15}$ 
27 Neste quadro de insuficiências que se alimentam mutuamente, a sensibilização é um factor decisivo para romper impasses. A que tem sido efectuada em Portugal é pouca, regra geral girando à volta de alertas avulsos sobre a destruição (ou ameaça de destruição) de parte do património. Recentemente foi realizado um encontro específico, que, pelo seu pioneirismo, qualidade e impacto, merece referência própria.

O encontro teve a forma de um painel realizado no âmbito do 11.. Congresso Nacional de Bibliotecários, Arquivistas e Documentalistas, intitulado «As editoras e o seu património: preservar, disponibilizar e divulgar como medidas urgentes» e coordenado por Daniel Melo, do Centro de História da Cultura da Universidade Nova de Lisboa. ${ }^{16} \mathrm{O}$ fito principal era debater como preservar e divulgar a memória e o património (arquivístico, documental, artístico, etc.) das editoras, tendo o coordenador da mesa proposto dois desafios concretos aos oradores deste painel, todos eles representantes do mundo da edição e da cultura em Portugal:

29 1) de entre os meios que consideram mais eficientes para a salvaguarda, tratamento e disponibilização dos arquivos de editoras, quais abraçaram ou estão dispostos a abraçar (por exemplo, tratamento arquivístico, a título particular ou em cooperação; produção de exposições temporárias; criação duma Casa-Museu da Edição, para preservação de fundos e produção de mostras e catálogos; divulgação de documentos ou textos evocativos da acção editorial na internet, em espaços próprios ou cooperantes; concessão de entrevistas a estudiosos);

30 2) debater modalidades de cooperação institucional entre editores, Estado central, autarquias, associações profissionais, universidades, fundações, mecenas privados e outros, com vista à preservação, tratamento e acessibilidade dos arquivos das editoras, para fins de estudo (científico ou outro) e divulgação cultural (exposições, catálogos, informação na internet), independentemente de o arquivo continuar na posse da entidade produtora (ou de herdeiros particulares) ou passar para a guarda dum serviço de arquivo (estatal, de instituições de utilidade pública ou de beneméritos).

31 Para reflectir sobre o tema intervieram João Alvim (presidente da APEL e administrador da Bertrand e Círculo de Leitores), João Corregedor da Fonseca (da Seara Nova), José Pacheco Pereira (coleccionador, bibliófilo e divulgador através dos sítios de internet Ephemera e Estudos sobre o Comunismo) e o editor-livreiro José Antunes Ribeiro (da Ulmeiro, Assírio \& Alvim, Livrarte, entre outras). No alargado período de debate aberto à audiência, destacaram-se as intervenções doutros especialistas, nomeadamente de Henrique Barreto Nunes (ex-director da Biblioteca Pública de Braga e actual dirigente da APBAD), Almerinda Graça (do Arquivo de Cultura Portuguesa Contemporânea da BNP), Maria José Vitorino (do Museu do Neo-Realismo), Cláudia Castelo (arquivista e historiadora, investigadora no Instituto de Investigação Científica e Tropical) e Pedro Santos (arquivista).

32 Foram seis as principais conclusões do encontro, em boa medida incorporadas nas próprias conclusões/votos do congresso, a saber:

33 1) foi salientado por todos o carácter inédito deste painel, permitindo debater uma dimensão importante do património cultural, dos bens culturais e dos arquivos da contemporaneidade;

34 2) foi consensual também a necessidade de envolvimento dos vários agentes do mundo do livro e da edição, bem como da arquivística, para se conseguir dar uma resposta o mais 
eficiente possível a esta questão (da salvaguarda, tratamento, disponibilização e divulgação dos arquivos de editoras);

3) foi destacada a importância da conjugação de esforços para se poderem dar respostas mais sistemáticas: assim, faz todo o sentido uma junção de competências, recursos e vontades por parte da APEL, da APBAD e de instituições públicas (a DGA, a CML e outras autarquias), em aliança com mecenas, editores e herdeiros, fundações e outros (por exemplo, a Sociedade Portuguesa de Autores, a Sociedade Portuguesa de Escritores, o PEN Clube);

4) vários dos intervenientes (oradores e público) denunciaram casos de perda de património de editoras e jornais relevantes, havendo o perigo de perdas maiores se não se encontrarem soluções eficientes e que tenham visibilidade (ou seja, que sejam do conhecimento dos detentores dos arquivos dessas editoras);

37 5) foi realçado por vários intervenientes (entre oradores e público) que a preservação da memória das casas editoriais deve ser acompanhada pela criação de condições para o estudo da respectiva documentação e pelo colmatar das suas lacunas através da produção de novas fontes históricas, por via de entrevistas, tarefa que deve envolver o máximo de instituições, para se conseguir ter testemunho do maior número possível de antigos editores, além de autores, empregados, etc.;

6) foram apresentadas e bem acolhidas certas propostas concretas:

39 a) a sensibilização para esta questão pela APBAD (por exemplo, via novos encontros temáticos, possibilidade de protocolos com a APEL);

b) o voluntariado por arquivistas (esta pode ser convertida em proposta consensual se equacionarmos o seguinte: os estágios dos mestrados de ciências documentais podem ser aproveitados para efectuar um tratamento inicial nestes arquivos - inventário preliminar, projecto de tratamento arquivístico/diagnóstico de necessidades, tempo de duração, materiais de acondicionamento e total de horas);

41 c) a feitura de um inquérito para levantamento dos arquivos de editoras existentes (a fazer circular pela APEL junto dos seus associados);

42 d) a consignação de infra-estruturas para acolhimento (incorporação) destes arquivos, que gozem de condições mínimas para conservação, tratamento e disponibilização da documentação, podendo compreender os equipamentos específicos dependentes da Direcção-Geral de Arquivos (Arquivo Nacional da Torre do Tombo e outros), espaços próprios facultados por municípios, beneméritos e/ou a criação de uma instituição própria (como o modelo do IMEC, em França).

43 Uma ressalva feita é a de que o Estado não tem necessariamente que acudir à preservação dos arquivos de editoras privadas, dado a tutela ser particular. Todavia, faz sentido procurar-se estabelecer parcerias para uma resolução mais diligente e eficiente dos impasses actuais, pois o financiamento estatal e/ou o mecenato cultural de empresa ou fundacional são manifestamente insuficientes, mormente nas áreas de infra-estruturas e equipamentos (vd. Santos \& Conde, 1990: 434; Santos, 1998: 268-279; Frada, 2001: 11-12 e passim, Gomes \& Martinho, 2011: 20).

Um aspecto que pode bloquear uma maior participação dos cidadãos a título particular/ filantrópico é a possibilidade de a legislação em preparação para as fundações ser impeditiva da existência de estruturas mais leves em termos de recursos humanos. Essa ameaça foi denunciada por José Pacheco Pereira, que deu o exemplo do perigo que pende 
sobre o seu próprio projecto: o de inviabilizar a criação de uma fundação para albergar a documentação que recolheu nas últimas décadas sobre história e cultura contemporâneas e a sua biblioteca, actualmente com cerca de 110 mil títulos e provavelmente a maior biblioteca privada portuguesa.

A nível mecenático fundacional foi referido que existe um financiamento específico da Fundação Calouste Gulbenkian (FCG) para a salvaguarda de arquivos. Trata-se do Concurso Recuperação, Tratamento e Organização de Acervos Documentais, criado em 2008 «para apoio à recuperação, tratamento e organização de acervos documentais com relevante interesse histórico, cultural e científico». ${ }^{17}$ Apesar da boa oportunidade desta iniciativa, o seu orçamento é relativamente modesto (máximo de quinze mil euros por entidade beneficiária) e as instituições interessadas (universitárias ou outras) apenas podem candidatar um projecto por ano, sendo depois eleita para financiamento apenas uma parte das candidaturas. Ademais, o plano de pagamentos pode ser interpretado como excessivamente burocratizado e lento (cf. artigo 11) e várias "despesas não elegíveis» ${ }^{18}$ são essenciais para se conseguir a salvaguarda dos arquivos a curto e médio prazo, pois muitos deles necessitam ser transferidos de espaços sem condições de preservação e/ou acesso para espaços adequados, seja para as tarefas de tratamento, limpeza e acondicionamento em suportes adequados da documentação, seja para dar um impulso inicial na alocação dum espaço condigno para serem instalados e disponibilizados à consulta pública. A FCG tem ainda uma outra linha de financiamento passível de reconhecer apostas na salvaguarda de arquivos históricos de editoras, que é o Prémio Vasco Vilalva (desde 2008), no valor de cinquenta mil euros, «destinado a assinalar intervenções exemplares em bens móveis e imóveis de valor cultural que estimulem a preservação e a recuperação do Património». ${ }^{19}$

Outra vertente que foi salientada é a de que os arquivos podem ser úteis para se aprofundar múltiplos níveis de conhecimento e da aç̧ão humana. No caso concreto dos arquivos de editoras, estes convocam não só as dimensões social e cultural como também as dimensões económica, política e institucional, porquanto os editores são agentes institucionais que articulam cultura e negócio em sentido lato. ${ }^{20}$ Nesse sentido, a preservação dos arquivos de editores é não só importante para uma história das actividades económicas, dos mediadores culturais e das relações entre política e cultura, etc., como para abordagens mais circunscritas, como a duma história empresarial. ${ }^{21}$

As intervenções, o debate e as conclusões do encontro revelaram muitos paralelos com a própria discussão mais técnico-científica, normativa e político-institucional que está ocorrendo presentemente a nível internacional no interior das instituições ligadas às ciências documentais.

Com efeito, os arquivos das editoras enquadram-se no conjunto de tipologias de arquivos que são regularmente objecto de apreciações e normas técnicas a nível internacional por parte da entidade mais representativa, o Conselho Internacional de Arquivos, cujo documento mais relevante é a recente «Declaração Universal sobre os Arquivos», de 2010 (http://www.ica.org/download.php?id=1484). Nele se enumeram todas as dimensões relevantes destes bens culturais, indo do património à administração, cuja preservação e acesso é assim fulcral para a saúde das sociedades e das democracias. ${ }^{22}$ Nesse sentido, preconiza-se um conjunto de medidas concretas para serem aplicadas a nível de cada Estado-nação: 1) legislação e medidas políticas adequadas para a arquivística; 2) valorização da gestão de arquivos por todos os organismos públicos e privados, incluindo a disponibilização dos recursos indispensáveis (contratação de profissionais capacitados); 
3) uma gestão dos arquivos que garanta autenticidade, integridade, uso e acesso a todos, de acordo com a legislação pertinente e os direitos de indivíduos, produtores, proprietários e usuários; 4) uso dos arquivos para promover uma cidadania responsável.

\section{BIBLIOGRAPHY}

ALEXANDRINO, José de Melo (s. d.), "O conceito de bem cultural”, Área Científica de Direito - IPBeja [Consult. 20 de Outubro, 2012]. Disponível em: <URL: http://www.estig.ipbeja.pt/ ac_direito/ JMABC.pdf>.

AMERICAN PRINTING HISTORY ASSOCIATION (s. d.), “The Oral History Project”, American Printing History Association [Consult. 15 de Março, 2012]. Disponível em: <URL: http:// www.printinghistory.org/programs/oral-history.php>.

ANSELMO, Artur (1997a), “A edição romântica”, in Estudos de História do Livro, Lisboa, Guimarães Editores, 1997, pp. 117-28.

ANSELMO, Artur (1997b), “O comércio livreiro de obras em fascículos”, in Estudos de História do Livro, Lisboa, Guimarães Editores, pp. 143-53.

AZEVEDO, Cândido de (1997), Mutiladas e Proibidas. Para a história da censura literária em Portugal nos tempos do Estado Novo, Lisboa, Editorial Caminho.

AZEVEDO, Cândido de (1999), A Censura de Salazar e Marcelo Caetano. Imprensa - teatro - cinema televisão - livro, Lisboa, Editorial Caminho.

BEJA, Rui (2012), A Edição em Portugal, 1970-2010. Percursos e perspectivas, Lisboa, APEL.

BRADLEY, Sue (2009), The British Book Trade. An oral history, Londres, The British Library.

BRAIDA, Lodovica; CADIOLI, Alberto (ed.) (2007), Testi, forme e usi del libro. Teorie e pratiche di cultura editoriale, Milão, Sylvestre Bonnard.

BRITISH LIBRARY (s. d.), "National life stories: Book Trade Lives", British Library [Consult. 15 de Março, 2012]. Disponível em: <URL: http://www.bl.uk/reshelp/findhelprestype/sound/ohist/ ohnls/nlsbook/book.html>.

BRUNETTI, Dimitri (org.) (2011), Gli archivi storici delle case editrici, Turim, Centro Studi Piemontesi.

CADIOLI, Alberto; DECLEVA, Enrico; SPINAZZOLA, Vittorio (ed.) (1999), La mediazione editoriale, Milão, Il Saggiatore.

CAEIRO, Francisco da Gama (1980), Livros e Livreiros Franceses em Lisboa, nos fins de setecentos e primeiro quartel do século XIX, Coimbra, Coimbra Editora.

CHARON, Annie; PARINET, Élisabeth (2011), Bibliographie sélective d'histoire du livre, Paris, École Chartes.

CLERICI, Luca et al. (org.) (2000), Bibliografi a 1980-1998, Milão, Il Saggiatore/Fondazione Arnoldo e Alberto Mondadori. 
COELHO, Jacinto do Prado, et al. (1980), Problemática da Leitura - Aspectos sociológicos e pedagógicos, Lisboa, INIC.

COELHO, José Teixeira (1999), Dicionário de política cultural, São Paulo, Iluminuras.

COLES, Laura Millar (1989), Archival Gold. Managing and preserving publisher's records, Vancouver, Canadian Centre for Studies in Publishing.

COLUMBIA CENTER FOR ORAL HISTORY (s. d.), "Columbia University Oral History Research Office - About", Facebook - Columbia University Oral History Research Offi ce [Consult. 20 de Outubro, 2012]. Disponível em: <URL: http://www.facebook.com/pages/Columbia-University-OralHistoryResearch-Office/194451799101?sk=info>.

CORDÓN, José Antonio (2003), “La edición electrónica en el contexto de los estudios sobre edición contemporánea en España", L \& b [Consult. 24 de Outubro, 2012]. Disponível em: <URL: http:// jamillan.com/celcor.htm>.

COSTA, Sara Figueiredo (2012), Fernando Guedes: 0 decano dos editores portugueses, Lisboa, Booktailors.

CRAVO, Nuno Filipe Ramalho (2009), Civilização Editora - 130 anos no universo familiar dos livros, Aveiro, Universidade de Aveiro, tese de mestrado.

CURTO, Diogo Ramada (2003), Bibliografia da História do Livro em Portugal: Séculos XV a XIX, Lisboa, Biblioteca Nacional.

CURTO, Diogo Ramada (dir.) (2006), Estudos de Sociologia da Leitura em Portugal no Século XX, Lisboa, Fundação Calouste Gulbenkian e Fundação para a Ciência e a Tecnologia.

DOMINGOS, Manuela D. (1985), Estudos de Sociologia da Cultura. Livros e leitores no séc. XIX, Lisboa, IPED.

DOMINGOS, Manuela D. (coord.) (2002), Estudos sobre História do Livro e da Leitura em Portugal, 1995-2000, Lisboa, Biblioteca Nacional.

ELIOT, Simon; ROSE, Jonathan (eds.) (2007), A Companion to History of the Book, Oxford/Nova Iorque, Blackwell Publishing Ltd.

FAURE, Chantal (2003), Catalogues de libraires et d'éditeurs, 1811-1924, Paris, Bibliothèque Nationale de France.

FERRÃO, Manuela; OLIVEIRA, Susana; FONSECA, Teresa (orgs.) (2005), Livros Proibidos no Estado Novo, Lisboa, Assembleia da República.

FERREIRA, Jerusa Pires (2004), "Por uma memória do livro, da vida e do ofício: o projeto Editando o editor", in I Seminário Brasileiro Livro e História Editorial, Rio de Janeiro, Fundação Casa Rui Barbosa, pp. 1-7 [Consult. 2 de Outubro, 2012]. Disponível em: <URL: http://

www.livroehistoriaeditorial.pro.br/pdf/jerusapires.pdf>.

FINKELSTEIN, David; BROMAGE, Sarah; McCLEERY, Alistair (2002), "Scottish Archive of Print and Publishing History Records", Learned Publishing, vol. 15, n. 3, pp. 193-197 [Consult. 2 de Outubro, 2012]. Disponível em: <URL: http://eresearch.qmu.ac.uk/210/1/eResearch_210.pdf>.

FONDAZIONE ARNOLDO E ALBERTO MONDADORI (1999-2005), "Risorse per la conservazione", Fondazione Arnoldo e Alberto Mondadori [Consult. 2 de Novembro, 2012]. Disponível em: <URL: http://www.fondazionemondadori.it/cms/conservazione/30/intro-censimenti>.

FOUCHÉ, Pascal; PÉCHOIN, Daniel; SCHUWER, Philippe (2002-2011), Dictionnaire encyclopédique du livre, Paris, Éditions du Cercle de la Librairie, 3 vols. 
FRADA, Joana (2001), O Mecenato Cultural de Empresa em Portugal, Lisboa, ISCSP-UTL, relatório da licenciatura em Comunicação Social.

FREITAS, Eduardo de (2008), "Para uma sociologia do livro e da leitura. Bibliografia Portuguesa de Livros (nova versão revista e actualizada)", Theca Libraria, [Consult. 5 de Novembro, 2012]. Disponível em: <URL: http://www.box.net/shared/hbrin7xmek>.

FURTADO, José Afonso (2007), o Papel e o Pixel - Do impresso ao digital, Lisboa, Ariadne.

FURTADO, José Afonso (2009), A Edição de Livros e a Gestão Estratégica, Lisboa, Booktailors.

GABINETE INTERDISCIPLINAR DO LIVRO E DA LEITURA (1997), “350 títulos para a história do livro e da leitura em Portugal”, Cultura, vol. IX, série II, pp. 314-335.

GOMES, Rui Telmo; MARTINHO, Teresa Duarte (2011), Compendium of Cultural Policies and Trends in Europe. Country profile - Portugal, 12. ed., s. 1., Council of Europe/ERICarts.

GUEDES, Fernando (1989), O Livro e a Leitura em Portugal. Subsídios para a sua história, séculos XVIII e XIX, Lisboa, Verbo.

GUEDES, Fernando (1993), Os Livreiros em Portugal e as suas Associações desde o Século XV até aos Nossos Dias, Lisboa, Verbo.

IMEC (2009), “Colloque 20 Ans de Recherches sur l'Édition”, IMEC [Consult. 24 de Outubro, 2012]. Disponível em: <URL: http://www.imec-archives.com/activites_prgm/imec_20091030_381.pdf>.

IMEC (2011a), “Mémoire vivante de l'écrit, de l'édition et de la création”, IMEC [Consult. 25 de Outubro, 2012]. Disponível em: <URL: http://www.imec-archives.com/imec.php>.

IMEC (2011b), “Activités ”, IMEC [Consult. 25 de Outubro, 2012]. Disponível em: <URL: http:// www.imec-archives.com/activites.php>.

LAMBERT, Simon (2010), "Italy and the history of preventive conservation", CeROARt, hors-série [Consult. 6 de Novembro, 2012]. Disponível em: <URL: http://ceroart.revues.org/1707>.

LEITE, Pedro (1998), Mercadores de Letras. Rumos e estratégias dos editores e livreiros na divulgação cultural durante o Estado Novo (1933-1974), Lisboa, FLUL, tese de mestrado.

LISBOA, João Luís (1997), "Sobre a investigação actual em história do livro e da leitura”, Leituras, Revista da Biblioteca Nacional, n.ำ 1, pp. 105-112.

MARCHETTI, Ada Gigli, et al. (ed.) (2003), Editori italiani dell'Ottocento. Repertorio, Milão, Franco Angeli.

MARTINS, Jorge M. (1999), Marketing do Livro. Materiais para uma sociologia do editor português, Oeiras, Celta.

MARTINS, Jorge M. (2004), Sociologia do Livro: 0 campo da mediação na era digital, Lisboa, ISCTE, tese de doutoramento.

MARTINS, Jorge M. (2005), Profissões do Livro: Editores e gráficos, críticos e livreiros, Lisboa, Verbo.

MATOS, Manuel Cadafaz de (2007), "Para a história do livro, da edição e da censura no século XX: a perspectiva de Aquilino como investigador e na correlação com os estudos clássicos e humanísticos", Revista «Letras Aquilinianas», n.․ 1, pp. 161-187.

MAUÉS, Flamarion (2012), “A edição política em Portugal: do combate à ditadura à revolução dos cravos", Revista Eletrônica Literatura e Autoritarismo, n.. de Maio, pp. 313-341.

MEDEIROS, Nuno (2010), Edição e Editores. $O$ mundo do livro em Portugal, 1940-1970, Lisboa, Imprensa de Ciências Sociais. 
MENDES, José Amado (2001-2002), “Arquivos empresariais: história, memória e cultura de empresa”, Revista Portuguesa de História, tomo XXXV, pp. 379-388.

MICHON, Jacques; MOLLIER, Jean-Yves (dir.) (2001), Les Mutations du livre et de l'édition dans le monde du XVIIIe siècle à l'an 2000, Saint-Nicolas - Paris, Presses de l'Université Laval/L'Harmattan.

MILLAR, Laura (2009), The Story behind the Book. Preserving authors' and publishers' archives, Vancouver, CCSP Press Books.

NEVES, José Soares; SANTOS, Jorge Alves dos (2010), Edição e Comercialização de Livros em Portugal: Empresas, volume de negócios e emprego (2000-2008), Lisboa, Observatório das Actividades Culturais, [Consult. 31 de Outubro, 2012]. Disponível em: <URL: http://www.oac.pt/pdfs/ OAC_EdicaoComercializacaoDeLivros_Portugal\%202000-2008.pdf>.

NEVES, José Soares (coord.) (2012), Inquérito ao Sector do Livro, Lisboa, Observatório das Actividades Culturais, 2 vols.

PEREIRA, Antónia Maria (1998), Parceria A. M. Pereira. Crónica de uma dinastia livreira, Lisboa, Pandora.

OLLION, Martine (1999), "Défense et illustration d'un patrimoine méconnu: les archives des maisons d'édition", Bulletin d'informations de l'ABF, n. ${ }^{\circ} 183$, pp. 46-50 [Consult. 30 de Outubro, 2012]. Disponível em: <URL: http://www.enssib.fr/bibliotheque-numerique/revues/ afficher-46595\#notebaspage_10>.

PEREIRA, Luís Filipe Raposo (2011), "Documento de arquivo e documento bibliográfico como bens culturais: evolução registada e factores de afirmação”, Páginas a\&b, s. II, n.ำ 8, pp. 149-160 [Consult. 25 de Outubro, 2012]. Disponível em: <URL: http://dc401.4shared.com/doc/ ZISUZ5cr/ preview.html>.

PINHEIRO, Maria Odete Manso (coord.) (2007), António Carlos Manso Pinheiro. Uma homenagem, Lisboa, Estampa e APEL.

POULOT, Dominique (1998), Musée, nation, patrimoine 1789-1815, Paris, L'Harmattan.

PRATAS, Maria Manuela R. S.; LOPES, Paula Ferreira (1974), "Subsídios bibliográficos para a história do livro em Portugal”, in Actas do IV Encontro de Bibliotecários, Arquivistas e Documentalistas Portugueses, Coimbra, FLUC, pp. 427-450.

RÊGO, Manuela; CASTELO-BRANCO, Miguel (coord.) (2003), Antes das Playstations: 200 anos do romance de aventuras em Portugal, Lisboa, Biblioteca Nacional.

RIBEIRO, Fernanda (2008), Para o Estudo do Paradigma Patrimonialista e Custodial. A Inspecção das Bibliotecas e Arquivos e o contributo de António Ferrão (1887-1965), Porto, CETAC.Media/ Afrontamento.

RIBEIRO, Maria Manuela Tavares (1999), "Livros e leituras no século XIX”, Revista de História das Ideias, vol. 20, pp. 187-227.

RODRIGUES, A. A. Gonçalves (1992-94 e 1999), A Tradução em Portugal, Lisboa, ICALP, 5 vols.

SANTOS, Maria de Lourdes Lima dos (1985), “As penas de viver da pena (aspectos do mercado nacional do livro no século XIX)”, Análise Social, vol. XXI, n. 86, pp. 187-227.

SANTOS, Maria de Lourdes Lima dos; CONDE, Idalina (1990), "Mecenato cultural de empresa em Portugal", Análise Social, vol. XXV, n.․107, pp. 375-439.

SANTOS, Maria de Lourdes Lima dos (ed.) (1998), As Políticas Culturais em Portugal, Lisboa, Observatório das Actividades Culturais. 
SARAIVA, José António (1979), Bertrand, a história de uma editora, Lisboa, Livraria Bertrand.

SERUYA, Teresa (org.) (2005), Estudos de tradução em Portugal. A Colecção Livros RTP-Biblioteca Básica Verbo - 1971-1972, Lisboa, Universidade Católica Editora.

SERUYA, Teresa (org.) (2007), Estudos de Tradução em Portugal. A colecção Livros RTP-Biblioteca Básica Verbo - II, Lisboa, Universidade Católica Editora.

TORTORELLI, Gianfranco (dir.) (1998), Gli archivi degli editori. Studi e prospettive di ricerca, Bolonha, Patron.

TRANIELLO, Paolo (1997), La biblioteca pubblica. Storia di un istituto nell'Europa contemporanea, Bolonha, Il Mulino.

\section{NOTES}

1. Alexandrino, s. d.; Lambert, 2010; Pereira, 2011. Note-se que as 84 recomendações da Comissão Franceschini foram sintetizadas em nove recomendações para aplicação urgente, sendo que pelo menos três interessam directamente aos arquivos de editoras: a) estabelecer um serviço de segurança para proteger a herança cultural; b) iniciar um inventário sistemático da herança cultural; c) estabelecer núcleos para pesquisa, conservação e restauro, e institutos de documentação (Lambert, 2010: 6/7).

2. Lambert, 2010: 7-12 e 2 (cit. da definição do Conselho Internacional de Museus em Lambert, 2010: 2).

3. Cf. preâmbulo do diploma em http://www.dgpj.mj.pt/DGPJ/sections/leis-da-justica/livro-ivleis-criminais/pdf3/dl-16-1993/downloadFile/file/DL_16_1993.pdf?nocache=1181840369.94.

4. Especialmente nos seus arts. 4, 15-17, 31, 72 e 80-86 ( http://dgarq.gov.pt/ files/2008/10/107_2001.pdf ). Um dos aspectos clarificados é o conjunto de critérios que sustentam o pedido de classificação dos bens arquivísticos: «Para a classificação ou o inventário do património arquivístico, devem ser tidos em conta algum ou alguns dos seguintes critérios: a) Natureza pública da entidade produtora; b) Relevância das actividades desenvolvidas pela entidade produtora num determinado sector; c) Relevância social ou repercussão pública da entidade produtora; d) Valor probatório e informativo do arquivo, decorrente, nomeadamente, da sua relevância jurídica, política, económica, social, cultural, religiosa ou científica» (art. 82). Para os bens culturais em geral o diploma prescreve um conjunto mais extenso de «critérios genéricos de apreciação» do pedido de classificação ou inventariação (vd. art. 17).

5. Uma boa panorâmica das múltiplas dimensões tocadas pela edição é-nos dada por Lisboa (1997: 105-112): «Em torno do livro convergem muitos olhares. O livro é trabalhado como mercadoria, como objecto de consumo, como elemento de distinção social, como manifestação de poder, como instrumento de intervenção, como veículo de ideias, novas ou não, como suporte de formas de expressão, como registo de memória, como recurso de administração, como resultado de um trabalho artesanal, como testemunho de manuseamentos quotidianos, como materialização de uma estética.»

6. Destaco as seguintes linhas: a) subvenção para as plataformas inovadoras de difusão e de valorização de catálogos de livros digitais; $b$ ) subvenção para a digitalização retrospectiva e a difusão via Internet de documentos ainda sob a alçada de direitos de propriedade literária; $c$ ) subvenções à criação e ao desenvolvimento de sites colectivos de editores e de livreiros (http:// www.centrenationaldulivre.fr/?-Aides-aux-publications-). Sobre o historial deste organismo, originalmente designado por Caisse Nationale des Lettres, vd. http://fr.wikipedia.org/wiki/ Centre_national_du_Livre. 
7. A lista bibliográfica é tão extensa que apenas cabe reenviar para algumas obras colectivas de referência com ambição transnacional (Michon \& Mollier, 2001; Fouché, Péchoin \& Schuwer, 2002-2011; Elliot \& Rose, 2007) e salientar estar nos EUA e França a produção de maior relevo, acompanhados de perto por Reino Unido, Itália, Espanha e Brasil. Realce ainda para um estudo específico sobre arquivos editoriais enquanto património ao serviço da pesquisa científica (Ollion, 1999) e para o balanço europeu em IMEC, 2009.

8. Cf. http://editeurslesloisdumetier.bpi.fr/bpi_loi-edition/fr/. A França concentra diversas outras boas práticas no domínio da edição sectorial, de acções formativas, por exemplo, através do Cercle de la Librarie e do Syndicat National de l'Édition (Martins, 1999: 19-21).

9. Cf. algumas no sítio de Internet da SHARP (< http://www.sharpweb.org/index.php? option=com_content\&view=article\&id=5\&Itemid=57\&lang=en $>$ ).

10. Para França, v.g., Faure, 2003 e Charon \& Parinet, 2011; para Itália, v.g. Fondazione Arnoldo e Alberto Mondadori, 1999-2005 (respeitante aos censos dos arquivos de editores de seis províncias italianas: Lombardia, Toscana, Veneto, Friuli Veneza Giulia, Trentino Altro Adige e Ligúria), Clerici, et al., 2000 e Marchetti et al., 2003.

11. No caso da história oral, a única instituição desde início com vocação para a produção e guarda de entrevistas foi o Centro de Documentação 25 de Abril da Universidade de Coimbra, mas limitadas à temática da II República Portuguesa. Recentemente também o Instituto de Ciências Sociais da Universidade de Lisboa acolheu um conjunto de entrevistas relativas ao tema da guerra colonial.

12. Está colocando recentemente na internet alguma documentação de editores e média, como por exemplo de Francisco Lyon de Castro, dos jornais Diário de Lisboa e O Diabo, da revista O Tempo e o Modo e outras, através do seu projecto Casa Comum - cf. http://www.casacomum.org/cc/ arquivos.

13. Em Portugal a situação é mais grave, dado o atraso na instauração dos mecanismos de salvaguarda. Para os casos holandês e grego, vd. relatos de Adriaan van der Weel e Catherine Velissaris, respectivamente, em IMEC, 2009: 18. Para o caso espanhol, vd. Cordón, 2003.

14. Balanço partilhado por, entre outros, Martins, 1999: 19. Quanto a bibliografia específica, vd. guias Pratas \& Lopes, 1974; Gabinete Interdisciplinar do Livro e da Leitura, 1997; Domingos, 2002; Curto, 2003; e Freitas, 2008. Note-se que no 2. guia, acima de $40 \%$ são livros do último decénio (1986-96), o 3. só colecta 1995-2000, no 4.ำ a listagem finda no século XIX e o 5.ํ só abrange a sociologia do livro e da leitura. A enumeração bibliográfica que se segue exclui quase todas as obras predominantemente sobre tipógrafos, imprensa, publicações periódicas, livreiros, censura e leitura pública, por não ser esse o escopo deste trabalho e por estas áreas estarem mais trabalhadas (talvez com excepção das três últimas).

15. Vd. Varela \& Ramos, 1984 e Gaspar et al., 1992 na obra supracitada.

16. Lisboa, Fundação Calouste Gulbenkian, 18/10/2012, vd. programa em http:// www.bad.pt/11congresso/.

17. Vd. http://www.gulbenkian.pt/section65artId1571langId1.html.

18. Diz o artigo 5 do regulamento do concurso de 2012 que «Não são, designadamente, suscetíveis de financiamento as despesas com: a) Remunerações certas e permanentes; b) Amortização de equipamentos; c) Manutenção de equipamentos; d) Aquisição ou arrendamento de terrenos ou edifícios; e) Construção ou reabilitação de edifícios; f ) Encargos com dívidas; g) Assinatura ou aquisição de publicações periódicas; h) Aquisição ou aluguer de viaturas; i) Funcionamento corrente das instituições, como sejam gastos de água, eletricidade e gás» (das rubricas excluídas de eventual apoio as mais penalizadoras para a sustentabilidade dos arquivos são as constantes das alíneas $b, c, d$ e $i$ ).

19. Vd. http://www.gulbenkian.pt/section25artId154langId1.html.

20. A este propósito, vd. Cadioli, Decleva \& Spinazzola, 1999 e Martins, 1999: 31-57. 
21. Sobre a importância da salvaguarda e estudo dos arquivos empresariais, vd. Mendes, 2001-2002.

22. Como se refere no documento: «Arquivos registram decisões, ações e memórias. Arquivos são um património único e insubstituível transmitido de uma geração a outra. Documentos de arquivo são geridos desde a criação para preservar seu valor e significado. Arquivos são fontes confiáveis de informação para ações administrativas responsáveis e transparentes. Desempenham um papel essencial no desenvolvimento das sociedades ao contribuir para a constituição e salvaguarda da memória individual e coletiva. O livre acesso aos arquivos enriquece o conhecimento sobre a sociedade humana, promove a democracia, protege os direitos dos cidadãos e aumenta a qualidade de vida.»

\section{ABSTRACTS}

Quando se fala em património cultural, uma área que costuma ficar na penumbra é a dos arquivos históricos. De entre estes, um dos conjuntos mais vulneráveis é o dos arquivos de editoras e outros agentes da edição. Este artigo propõe uma reflexão em torno do património arquivístico em geral e dos arquivos das editoras em particular, a nível internacional. Tal digressão analítica e problematizante serve, em boa medida, para ajudar a repensar o caso português, cujos atrasos e impasses urge solucionar, sob pena de se perderem irremediavelmente fontes preciosas para o conhecimento da nossa contemporaneidade. Em complemento, e a partir de um encontro específico organizado pelo autor, segue-se um conjunto de reflexões de distintos agentes do meio cultural, da autoria de José Pacheco Pereira, João Corregedor da Fonseca e José Antunes Ribeiro.

When it comes to cultural heritage, an area that tends to stay in the shadows is the historical archives. Of these, one of the most vulnerable groups is the publishers' archives (and the archives of other agents of the publishing world). This article proposes a reflection on cultural heritage in general and on cultural heritage specifically related to publishers' archives, in an international level. This analytical and problematizing tour-de-force serves, to a large extent, to help to rethink the Portuguese case, whose delays and impasses need to be solved urgently, for the risk of losing irretrievably precious sources for the knowledge of our contemporaneity is serious. In addition, and related with a specific meeting organized by the author, this article is followed by a set of reflections from distinctive cultural agents, such as José Pacheco Pereira, João Corregedor da Fonseca and José Antunes Ribeiro.

\section{INDEX}

Keywords: cultural heritage, historical archives, publishing, publishing history, archival policy, cultural policy, inter-institutional cooperation, collective memory

Palavras-chave: património cultural, arquivos históricos, edição, história da edição, política arquivística, política cultural, cooperação interinstitucional, memória colectiva 


\section{AUTHOR}

\section{DANIEL MELO}

Centro de História da Cultura da Faculdade de Ciências Sociais e Humanas da Universidade Nova de Lisboa.

Historiador e investigador auxiliar no Centro de História da Cultura da Faculdade de Ciências Sociais e Humanas da Universidade Nova de Lisboa (daniel.melo@fcsh.unl.pt). Doutorado em História contemporânea (ISCTE, 2003). Publicou os livros Salazarismo e Cultura Popular (Imprensa de Ciências Sociais, 2001) e A Leitura Pública no Portugal Contemporâneo (ICS, 2004), ambos Prémio de História Contemporânea Victor de Sá (Universidade do Minho) e resultantes de adaptações das teses de mestrado e doutoramento, respectivamente. Em 2010 actualizou essas pesquisas nos ensaios Estado Novo e Cultura Popular (Angelus Novus) e A Leitura Pública na I República (Húmus). É co-mentor do Seminário doutoral de História da Leitura e da Edição, a funcionar na FCSH desde 2011-12. Coordena ainda o projecto interdisciplinar e interuniversitário «Edição e cultura de massas (Romano Torres)», centrado na salvaguarda, estudo e divulgação do arquivo histórico daquela editora centenária. Tem como principais áreas de interesse: políticas culturais, leitura pública, história do livro e da edição, educação popular, associativismo sociocultural e migrações na contemporaneidade.

He is an Historian and a Research fellow at the Centro de História da Cultura (Centre for Cultural History) of the Universidade Nova de Lisboa since 2009 (daniel.melo@fcsh.unl.pt). He has written Salazarismo e Cultura Popular (1933-58) ['Salazarism and Popular Culture', 2001] and A Leitura P ública no Portugal Contemporâneo (1926-1987) ['Public reading in contemporary Portugal', 2004], both distinguished with the Contemporary History Prize 'Victor de Sá' and published by the academic publisher Imprensa de Ciências Sociais. Melo has recently updated and expanded those works, in the books Estado Novo e Cultura Popular (Angelus Novus) and A Leitura Pública na I República (Húmus), both in 2010. He is co-mentor of the postgraduate Seminar on the History of Reading and Publishing, taught at FCSH since 2011-12. He also coordinates the interdisciplinary and inter-universitary project «Mass publishing and mass culture (Romano Torres)», focused on the preservation, study and dissemination of the historical archive of that centennial publishing house. His main research areas are cultural policy, public reading, book history, publishing history, popular education, socio-cultural associations and migration in the contemporary age. 